\title{
Altered expression of Alzheimer's disease-related genes in the cerebellum of autistic patients: a model for disrupted brain connectome and therapy
}

\author{
F Zeidán-Chuliáa, ${ }^{\star 1}$, B-HN de Oliveira ${ }^{1}$, AB Salmina ${ }^{2}$, MF Casanova ${ }^{3}$, DP Gelain ${ }^{1}$, M Noda $^{4}$, A Verkhratsky ${ }^{5,6,7}$ and JCF Moreira ${ }^{1}$
}

Autism and Alzheimer's disease (AD) are, respectively, neurodevelopmental and degenerative diseases with an increasing epidemiological burden. The AD-associated amyloid- $\beta$ precursor protein- $\alpha$ has been shown to be elevated in severe autism, leading to the 'anabolic hypothesis' of its etiology. Here we performed a focused microarray analysis of genes belonging to NOTCH and WNT signaling cascades, as well as genes related to AD and apoptosis pathways in cerebellar samples from autistic individuals, to provide further evidence for pathological relevance of these cascades for autism. By using the limma package from $R$ and false discovery rate, we demonstrated that $31 \%$ (116 out of 374 ) of the genes belonging to these pathways displayed significant changes in expression (corrected $P$-values $<0.05$ ), with mitochondria-related genes being the most downregulated. We also found upregulation of GRIN1, the channel-forming subunit of NMDA glutamate receptors, and MAP3K1, known activator of the JNK and ERK pathways with anti-apoptotic effect. Expression of PSEN2 (presinilin 2) and APBB1 (or F65) were significantly lower when compared with control samples. Based on these results, we propose a model of NMDA glutamate receptor-mediated ERK activation of $\alpha$-secretase activity and mitochondrial adaptation to apoptosis that may explain the early brain overgrowth and disruption of synaptic plasticity and connectome in autism. Finally, systems pharmacology analyses of the model that integrates all these genes together (NOWADA) highlighted magnesium $\left(\mathrm{Mg}^{2+}\right)$ and rapamycin as most efficient drugs to target this network model in silico. Their potential therapeutic application, in the context of autism, is therefore discussed. Cell Death and Disease (2014) 5, e1250; doi:10.1038/cddis.2014.227; published online 22 May 2014

Subject Category: Neuroscience

Autism is a neurodevelopmental disorder characterized by specific activity patterns and aberrant social interaction and communication. ${ }^{1}$ Genetic and environmental factors have been proposed to account for apparently increasing rates of autism diagnostics. ${ }^{2,3}$ Its neurobiological basis is, however, poorly understood and the behavioral phenotypes display a high grade of heterogeneity, leading to the definition of 'autism spectrum disorders' (ASDs). It has been reported that clinical onset of ASD seems to be preceded by a phase of brain overgrowth in the first years of life followed by decreased growth rates between 5 and 12 years of age, when compared with controls. ${ }^{4}$ These abnormalities are paralleled by higher levels of brain-derived neurotrophic factor, insulin growth factors 1 and 2 (IGF-1 and IGF-2), IGF-binding protein 3, growth hormone-binding protein, neurotrophin-4, and a neuroinflammatory response in the ASD brains. ${ }^{5-8}$ Changes in trophic support may account for abnormal brain growth and an altered connectome, thus defining multiple ASD symptoms. Recent pieces of evidence also indicate the role for deregulated processing of the Alzheimer's disease $(\mathrm{AD})$-associated amyloid- $\beta(\mathrm{A} \beta)$ precursor protein (APP) in ASD-associated pathology. $A \beta$ is considered to be central for the pathophysiology of $A D$, which in its genetic and sporadic forms appears to be the most common cause of ageassociated dementia. AD is characterized by specific pathological hallmarks represented by extracellular deposits of fibrillar $\mathrm{A} \beta$, intraneuronal accumulation of neurofibrillary tangles due to hyperphosphorylation of cytoskeletal Tau filaments, as well as impairment of neurogenesis. The end result is massive neuronal death and consequent decline in cognitive functions. ${ }^{9-11}$ In ASD, the AD-associated APP, in particular its neuroprotective processing product or secreted $\operatorname{APP} \alpha(\operatorname{sAP} \alpha)$, was found to be elevated. ${ }^{12}$ Current research indicates that abnormalities of the cerebellum, now believed to

\footnotetext{
${ }^{1}$ Centro de Estudos em Estresse Oxidativo, Departamento de Bioquímica, Instituto de Ciências Básicas da Saúde, Universidade Federal do Rio Grande do Sul, Porto Alegre, Brazil; ${ }^{2}$ Department of Biochemistry, Medical, Pharmaceutical and Toxicological Chemistry, Krasnoyarsk State Medical University, Krasnoyarsk, Russia; ${ }^{3}$ Department of Psychiatry and Behavioral Sciences, University of Louisville, Louisville, KY, USA; ${ }^{4}$ Laboratory of Pathophysiology, Graduate School of Pharmaceutical Sciences, Kyushu University, Fukuoka, Japan; ${ }^{5}$ Faculty of Life Sciences, The University of Manchester, Manchester, UK; ${ }^{6}$ IKERBASQUE, Basque Foundation for Science, Bilbao, Spain and ${ }^{7}$ Department of Neurosciences, University of the Basque Country UPV/EHU, Leioa, Spain

${ }^{*}$ Corresponding author: F Zeidán-Chuliá, Centro de Estudos em Estresse Oxidativo, Departamento de Bioquímica, Instituto de Ciências Básicas da Saúde, Universidade Federal do Rio Grande do Sul, Rua Ramiro Barcelos 2600-ANEXO, Porto Alegre 90035-003, Rio Grande do Sul, Brazil. Tel: + 555133085577 ; Fax: + 55513308 5535; E-mail: fzchulia.biomed@gmail.com

Keywords: proliferation; mitochondria; APP; magnesium; rapamycin

Abbreviations: $\mathrm{A} \beta$, amyloid- $\beta$; AD, Alzheimer's disease; APP, amyloid- $\beta$ precursor protein; ASD, autism spectrum disorder; ER, endoplasmic reticulum; FDR, false discovery rate; GFAP, glial fibrillary acidic protein; HBs, hub-bottlenecks; IGF-1, insulin growth factor 1; IGF-2, insulin growth factor 2; NH-Bs, non-hub-bottlenecks; $\operatorname{SAPP} \alpha$, secreted amyloid- $\beta$ precursor protein $\alpha ; \operatorname{SAPP} \beta$, secreted amyloid- $\beta$ precursor protein $\beta$

Received 20.2.14; revised 13.4.14; accepted 16.4.14; Edited by D Bano
} 
have a role in cognitive function, are associated with autism; being one of the brain regions where cellular and growth abnormalities are most pronounced in the disorder. ${ }^{13-15}$

Here we address the question of whether changes of expression in the same set of genes observed in $A D$ neuropathology could also be found in autism; and if this is the case, whether drugs tested not only in the context of autism but also in AD may be considered for therapeutics in these patients. Our study shows altered expression of genes belonging to $\mathrm{NOTCH}, \mathrm{WNT}, \mathrm{AD}$, and apoptosis pathways in cerebellar samples from autistic individuals. In addition, systems pharmacology analyses of such a pathway that integrates $\mathrm{NOTCH}, \mathrm{WNT}, \mathrm{AD}$, and apoptosis-related genes suggest magnesium $\left(\mathrm{Mg}^{2+}\right)$ and rapamycin for further therapeutic exploration in the context of autism; two compounds/drugs that therapeutic use have already been discussed for different AD models. ${ }^{16,17}$

\section{Results}

Subnetwork analyses of AD-related pathways reveal transcriptional changes in the cerebellum of autistic individuals. For analyzing the potential transcriptional changes in genes belonging to pathways typically associated to AD pathology in autism, we constructed four subnetworks models of NOTCH (Supplementary Figure S1A), WNT (Supplementary Figure S2A), AD (Figure 1a), and apoptosis (Supplementary Figure S3A) pathways. These subnetworks contained 41, 136, 171, and 70 respective genes/proteins (Supplementary Tables S1-S4). Next, we performed a focused microarray analysis of the genes belonging to each subnetwork by using samples from the cerebellum of autistic patients versus controls. In $31 \%$ (116 out of 374 ) of the genes belonging to these in silico models were differentially expressed in ASD samples (corrected $P$-value $<0.05$ ) (Table 1). More specifically, $\sim 30 \%$ for NOTCH (12 genes), 23\% for WNT (31 genes), > 40\% for AD (69 genes), and $\sim 26 \%$ for apoptosis (18 genes). UQCRC1, NDUFS3, NDUFA9, JUN, CIDEB, CDC42, NDUFA6, NDUFB7, NDUFA1, and COX4I1 (Table 1) were the top 10 genes that displayed most significant changes in their expression. The downregulated genes were cytochrome $c$ reductase and NADH dehydrogenase related. Among the AD-related genes, upregulation of GRIN1, the channel-forming subunit of NMDA glutamate receptors, and MAP3K1, known activator of JNK and ERK pathways with

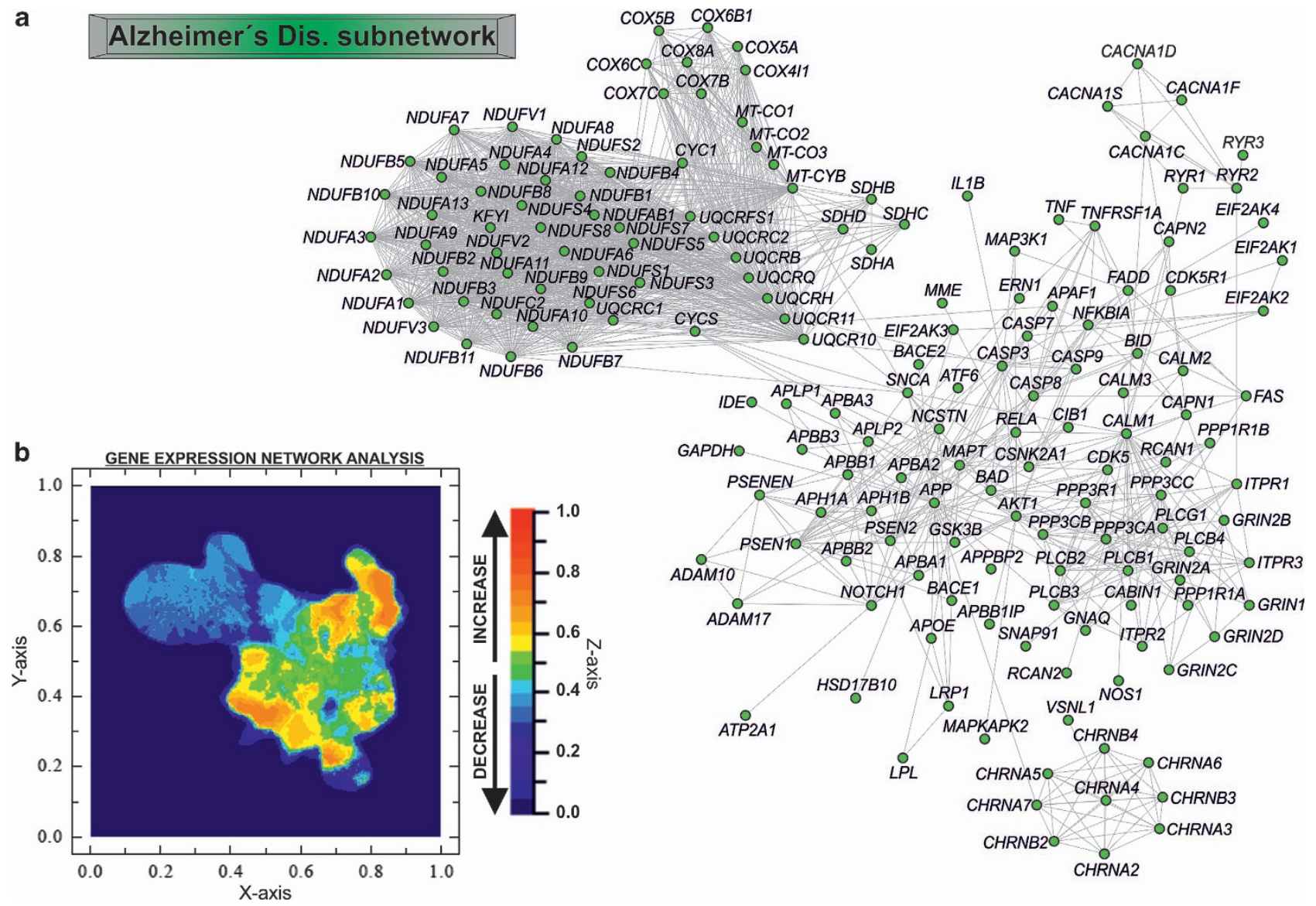

Figure 1 AD subnetwork analysis. (a) General landscape of interactions between genes/proteins belonging to the AD pathway (map05010; KEGG Pathway; http:// www.genome.jp/kegg/pathway.html). The in silico network model was developed by using the STRING 9.05 database resource search tool, under a confidence score of 0.600 and using 'Databases' and 'Experiments' as input options. (b) Focused microarray analyses of AD-related genes in the cerebellum of autistic patients versus healthy controls over the in silico model. The $z$ axis for representing the relative gene expression was constructed by using the ViaComplex software 
Table 1 Differentially expressed genes from the NOTCH, WNT, Alzheimer's disease, and apoptosis subnetworks in the cerebellum of autistic patients

\begin{tabular}{|c|c|c|c|c|c|}
\hline $\begin{array}{l}\text { Gene } \\
\text { symbol }\end{array}$ & Alias and/or description & $\begin{array}{l}\text { Ensembl ID } \\
\text { (ENSP) }\end{array}$ & $\begin{array}{l}\text { Differential gene } \\
\text { expression } \\
\text { (Up/down) }\end{array}$ & $\begin{array}{c}\text { Corrected } \\
\text { P-value } \\
\text { (FDR) }\end{array}$ & $\begin{array}{l}\text { Subnetwork } \\
\text { contribution/s }\end{array}$ \\
\hline UQCRC1 & Ubiquinol-cytochrome $c$ reductase core protein I & ENSP00000203407 & Down & 0.001062657 & AD \\
\hline NDUFS3 & $\begin{array}{l}\text { NADH dehydrogenase (ubiquinone) Fe-S protein } 3,30 \mathrm{kDa}(\mathrm{NADH}- \\
\text { coenzyme } \mathrm{Q} \text { reductase) }\end{array}$ & ENSP00000263774 & Down & 0.001722868 & $A D$ \\
\hline NDUFA9 & NADH dehydrogenase (ubiquinone) 1 alpha subcomplex, 9, $39 \mathrm{kDa}$ & ENSP00000266544 & Down & 0.00179604 & $A D$ \\
\hline$J U N$ & Jun oncogene & ENSP00000360266 & Up & 0.001921098 & WNT \\
\hline CIDEB & Cell death-inducing DFFA-like effector b & ENSP00000258807 & Down & 0.001949191 & APO \\
\hline$C D C 42$ & Cell division cycle 42 (GTP-binding protein, $25 \mathrm{kDa}$ ) & ENSP00000314458 & Down & 0.002000135 & WNT \\
\hline NDUFA6 & NADH dehydrogenase (ubiquinone) 1 alpha subcomplex, 6, $14 \mathrm{kDa}$ & ENSP00000330937 & Down & 0.002033295 & AD \\
\hline NDUFB7 & NADH dehydrogenase (ubiquinone) 1 beta subcomplex, $7,18 \mathrm{kDa}$ & ENSP00000215565 & Down & 0.002205663 & $A D$ \\
\hline NDUFA1 & NADH dehydrogenase (ubiquinone) 1 alpha subcomplex, $1,7.5 \mathrm{kDa}$ & ENSP00000360492 & Down & 0.002205663 & AD \\
\hline COX4I1 & Cytochrome $c$ oxidase subunit IV isoform 1 & ENSP00000253452 & Down & 0.002246413 & $A D$ \\
\hline NCSTN & Nicastrin & ENSP00000294785 & Up & 0.002354256 & AD NOT \\
\hline UQCRC2 & Ubiquinol-cytochrome $c$ reductase core protein II & ENSP00000268379 & Down & 0.002354256 & $A D$ \\
\hline NDUFS4 & $\begin{array}{l}\text { NADH dehydrogenase (ubiquinone) Fe-S protein } 4,18 \mathrm{kDa}(\mathrm{NADH}- \\
\text { coenzyme } \mathrm{Q} \text { reductase) }\end{array}$ & ENSP00000296684 & Down & 0.002459308 & $A D$ \\
\hline CYC1 & Cytochrome $c-1$ & ENSP00000317159 & Down & 0.002656014 & $A D$ \\
\hline COX8A & Cytochrome $c$ oxidase subunit $8 \mathrm{~A}$ (ubiquitous) & ENSP00000321260 & Down & 0.002656014 & $A D$ \\
\hline NDUFB4 & NADH dehydrogenase (ubiquinone) 1 beta subcomplex, 4, $15 \mathrm{kDa}$ & ENSP00000184266 & Down & 0.002688877 & $A D$ \\
\hline EIF2AK2 & Eukaryotic translation initiation factor 2-alpha kinase 2 & ENSP00000233057 & Up & 0.002850857 & $A D$ \\
\hline$B I D$ & BH3-interacting domain death agonist & ENSP00000318822 & Down & 0.002892499 & AD APO \\
\hline NDUFA4 & NADH dehydrogenase (ubiquinone) 1 alpha subcomplex, 4, $9 \mathrm{kDa}$ & ENSP00000339720 & Down & 0.003092192 & $\mathrm{AD}$ \\
\hline WNT3 & Wingless-type MMTV integration site family, member 3 & ENSP00000225512 & Up & 0.003122302 & WNT \\
\hline NDUFAB1 & NADH dehydrogenase (ubiquinone) 1, alpha/beta subcomplex, 1, $8 \mathrm{kDa}$ & ENSP00000007516 & Down & 0.003262718 & AD \\
\hline NDUFA11 & NADH dehydrogenase (ubiquinone) 1 alpha subcomplex, $11,14.7 \mathrm{kDa}$ & ENSP00000311740 & Down & 0.003262718 & $A D$ \\
\hline COX5A & Cytochrome $c$ oxidase subunit Va & ENSP00000317780 & Down & 0.003530677 & $A D$ \\
\hline$P R K C A$ & Protein kinase $\mathrm{C}$, alpha & ENSP00000284384 & Up & 0.003532751 & APO WNT \\
\hline NDUFB9 & NADH dehydrogenase (ubiquinone) 1 beta subcomplex, 9, $22 \mathrm{kDa}$ & ENSP00000276689 & Down & 0.003532751 & AD \\
\hline NDUFA2 & NADH dehydrogenase (ubiquinone) 1 alpha subcomplex, 2, $8 \mathrm{kDa}$ & ENSP00000252102 & Down & 0.003622328 & $A D$ \\
\hline$C O X 5 B$ & Cytochrome $c$ oxidase subunit $\mathrm{Vb}$ & ENSP00000258424 & Down & 0.003627494 & $A D$ \\
\hline$B C L 2$ & B-cell CLL/lymphoma 2 & ENSP00000329623 & Up & 0.003686548 & APO \\
\hline PRICKLE2 & Prickle homolog 2 (Drosophila) & ENSP00000295902 & Up & 0.003858642 & WNT \\
\hline$S D H B$ & Succinate dehydrogenase complex, subunit B, iron-sulfur (Ip) & ENSP00000364649 & Down & 0.003949261 & $\mathrm{AD}$ \\
\hline NDUFA10 & NADH dehydrogenase (ubiquinone) 1 alpha subcomplex, $10,42 \mathrm{kDa}$ & ENSP00000252711 & Down & 0.004023111 & $A D$ \\
\hline NDUFB2 & NADH dehydrogenase (ubiquinone) 1 beta subcomplex, 2, $8 \mathrm{kDa}$ & ENSP00000247866 & Down & 0.00417954 & $A D$ \\
\hline NDUFB6 & NADH dehydrogenase (ubiquinone) 1 beta subcomplex, 6, $17 \mathrm{kDa}$ & ENSP00000369176 & Down & 0.00420016 & $A D$ \\
\hline NDUFA7 & NADH dehydrogenase (ubiquinone) 1 alpha subcomplex, $7,14.5 \mathrm{kDa}$ & ENSP00000301457 & Down & 0.004449939 & $A D$ \\
\hline NDUFB3 & NADH dehydrogenase (ubiquinone) 1 beta subcomplex, $3,12 \mathrm{kDa}$ & ENSP00000237889 & Down & 0.004449939 & $A D$ \\
\hline UQCRB & Ubiquinol-cytochrome $c$ reductase-binding protein & ENSP00000287022 & Down & 0.004918915 & $A D$ \\
\hline NCOR2 & Nuclear receptor co-repressor 2 & ENSP00000348551 & Up & 0.005223194 & NOT \\
\hline LRP5 & Low density lipoprotein receptor-related protein 5 & ENSP00000294304 & Up & 0.005717875 & WNT \\
\hline$B A D$ & BCL2-associated agonist of cell death & ENSP00000309103 & Down & 0.005763042 & AD APO \\
\hline$U Q C R H$ & Ubiquinol-cytochrome $c$ reductase hinge protein & ENSP00000309565 & Down & 0.005906155 & AD \\
\hline PSEN2 & Presenilin 2 (Alzheimer disease 4 ) & ENSP00000355747 & Down & 0.005968353 & AD NOT \\
\hline NDUFA13 & NADH dehydrogenase (ubiquinone) 1 alpha subcomplex, 13 & ENSP00000380364 & Down & 0.00609761 & AD \\
\hline NDUFB10 & NADH dehydrogenase (ubiquinone) 1 beta subcomplex, 10, $22 \mathrm{kDa}$ & ENSP00000268668 & Down & 0.006262982 & $A D$ \\
\hline COX6C & Cytochrome $c$ oxidase subunit VIc & ENSP00000297564 & Down & 0.006681564 & $A D$ \\
\hline UQCRQ & Ubiquinol-cytochrome $c$ reductase, complex III subunit VII, $9.5 \mathrm{kDa}$ & ENSP00000367934 & Down & 0.00745614 & $A D$ \\
\hline NDUFA3 & NADH dehydrogenase (ubiquinone) 1 alpha subcomplex, $3,9 \mathrm{kDa}$ & ENSP00000398290 & Down & 0.007600014 & $A D$ \\
\hline HEY1 & Hairy/enhancer-of-split related with YRPW motif 1 & ENSP00000338272 & Down & 0.00784934 & NOT \\
\hline$D A A M 1$ & Disheveled associated activator of morphogenesis 1 & ENSP00000247170 & Up & 0.007909188 & WNT \\
\hline PPP3CC & Protein phosphatase 3 (formerly $2 \mathrm{~B}$ ), catalytic subunit, gamma isoform & ENSP00000240139 & Down & 0.008118636 & AD APO WNT \\
\hline$C O X 7 B$ & Cytochrome $c$ oxidase subunit VIIb & ENSP00000417656 & Down & 0.008265168 & $A D$ \\
\hline NDUFB11 & NADH dehydrogenase (ubiquinone) 1 beta subcomplex, $11,17.3 \mathrm{kDa}$ & ENSP00000276062 & Down & 0.008503556 & $A D$ \\
\hline NFKB1 & Nuclear factor of kappa light polypeptide gene enhancer in B cells 1 & ENSP00000226574 & Up & 0.008570685 & APO \\
\hline KAT2B & $\mathrm{K}$ (lysine) acetyltransferase $2 \mathrm{~B}$ & ENSP00000263754 & Up & 0.009111103 & NOT \\
\hline NDUFA12 & NADH dehydrogenase (ubiquinone) 1 alpha subcomplex, 12 & ENSP00000330737 & Down & 0.009479959 & $\mathrm{AD}$ \\
\hline UQCRFS1 & Ubiquinol-cytochrome $c$ reductase, Rieske iron-sulfur polypeptide 1 & ENSP00000306397 & Down & 0.009524703 & $A D$ \\
\hline NDUFS5 & $\begin{array}{l}\text { NADH dehydrogenase (ubiquinone) Fe-S protein } 5,15 \mathrm{kDa} \text { (NADH- } \\
\text { coenzyme } \mathrm{Q} \text { reductase) }\end{array}$ & ENSP00000362058 & Down & 0.009998423 & $A D$ \\
\hline$B A X$ & BCL2-associated $\mathrm{X}$ protein & ENSP00000293288 & Down & 538 & APO \\
\hline CYCS & Cytochrome $c$, somatic & ENSP00000307786 & Down & 0.010843806 & $A D$ \\
\hline NDUFV1 & NADH dehydrogenase (ubiquinone) flavoprotein 1, $51 \mathrm{kDa}$ & ENSP00000322450 & Down & 0.011017543 & $A D$ \\
\hline$R B X 1$ & Ring-box 1 & ENSP00000216225 & Down & 0.01185897 & WNT \\
\hline NFKBIA & $\begin{array}{l}\text { Nuclear factor of kappa light polypeptide gene enhancer in B cells } \\
\text { inhibitor, alpha }\end{array}$ & ENSP00000216797 & Up & 0.012804007 & AD APO \\
\hline AXIN2 & Axin 2 & ENSP00000302625 & Up & 0.01310984 & WNT \\
\hline CSNK1G1 & Casein kinase 1, gamma 1 & ENSP00000305777 & Up & 0.013381084 & WNT \\
\hline NDUFS8 & $\begin{array}{l}\text { NADH dehydrogenase (ubiquinone) Fe-S protein } 8,23 \mathrm{kDa} \text { (NADH- } \\
\text { coenzyme } \mathrm{Q} \text { reductase) }\end{array}$ & ENSP00000315774 & Down & 0.014197263 & $A D$ \\
\hline HSD17B10 & Hydroxysteroid (17-beta) dehydrogenase 10 & ENSP00000168216 & Down & 0.014254764 & $A D$ \\
\hline$R A C 3$ & $\begin{array}{l}\text { Ras-related C3 botulinum toxin substrate } 3 \text { (rho family, small GTP- } \\
\text { binding protein Rac3) }\end{array}$ & ENSP00000304283 & Down & 0.014704894 & WNT \\
\hline DTX3 & Deltex homolog 3 (Drosophila) & ENSP00000338050 & Down & 0.015144277 & NOT \\
\hline CDK5 & Cyclin-dependent kinase 5 & ENSP00000297518 & Down & 0.015567567 & $A D$ \\
\hline CABIN1 & Calcineurin-binding protein 1 & ENSP00000263119 & Up & 0.015953582 & AD WNT \\
\hline COX7C & Cytochrome $c$ oxidase subunit VIIc & ENSP00000247655 & Down & 0.016686515 & $A D$ \\
\hline RUVBL 1 & RuvB-like 1 (Escherichia coli) & ENSP00000318297 & Down & 0.016765972 & WNT \\
\hline$D F F A$ & DNA fragmentation factor, $45 \mathrm{kDa}$, alpha polypeptide & ENSP00000366237 & Up & 0.017000844 & APO \\
\hline NDUFB8 & NADH dehydrogenase (ubiquinone) 1 beta subcomplex, $8,19 \mathrm{kDa}$ & ENSP00000299166 & Down & 0.01782766 & $A D$ \\
\hline$C O \times 6 B 1$ & Cytochrome $c$ oxidase subunit VIb polypeptide 1 (ubiquitous) & ENSP00000246554 & Down & 0.017845204 & $A D$ \\
\hline TLE1 & Transducin-like enhancer-of-split 1 (E(sp1) homolog, Drosophila) & ENSP00000365682 & Up & 0.018030294 & NOT \\
\hline
\end{tabular}


Table 1 (Continued)

\begin{tabular}{|c|c|c|c|c|c|}
\hline $\begin{array}{l}\text { Gene } \\
\text { symbol }\end{array}$ & Alias and/or description & $\begin{array}{l}\text { Ensembl ID } \\
\text { (ENSP) }\end{array}$ & $\begin{array}{c}\text { Differential gene } \\
\text { expression } \\
\text { (Up/down) }\end{array}$ & $\begin{array}{l}\text { Corrected } \\
P \text {-value } \\
\text { (FDR) }\end{array}$ & $\begin{array}{c}\text { Subnetwork } \\
\text { contribution/s }\end{array}$ \\
\hline $\mathrm{NOTCH} 1$ & Notch homolog 1 & ENSP00000277541 & Up & 0.018222797 & AD NOT \\
\hline RYR2 & Ryanodine receptor 2 (cardiac) & ENSP00000355533 & Up & 0.019085894 & AD \\
\hline CACYBP & Calcyclin-binding protein & ENSP00000356652 & Down & 0.02050623 & WNT \\
\hline CSNK2B & Casein kinase 2 , beta polypeptide & ENSP00000415615 & Down & 0.02050623 & WNT \\
\hline SENP2 & SUMO1/sentrin/SMT3 specific peptidase 2 & ENSP00000296257 & Up & 0.021603075 & WNT \\
\hline CHD8 & Chromodomain helicase DNA-binding protein 8 & ENSP00000406288 & Up & 0.021898019 & WNT \\
\hline DTX2 & Deltex homolog 2 (Drosophila) & ENSP00000322885 & Up & 0.022277856 & NOT \\
\hline$S D H C$ & $\begin{array}{l}\text { succinate dehydrogenase complex, subunit } \mathrm{C} \text {, integral membrane } \\
\text { protein, } 15 \mathrm{kDa}\end{array}$ & ENSP00000356953 & Down & 0.023024554 & $A D$ \\
\hline$L R P 1$ & Prolow-density lipoprotein receptor-related protein 1 Precursor (LRP) & ENSP00000243077 & Up & 0.023159082 & $A D$ \\
\hline DLL1 & Delta-like 1 (Drosophila) & ENSP00000355718 & Up & 0.023184387 & NOT \\
\hline$A P B B 1$ & Amyloid beta (A4) precursor protein binding, family B, member 1 (Fe65) & ENSP00000299402 & Down & 0.024237411 & $A D$ \\
\hline MAP3K7 & Mitogen-activated protein kinase kinase kinase 7 & ENSP00000358335 & Down & 0.02453243 & WNT \\
\hline NDUFC2 & $\begin{array}{l}\text { NADH dehydrogenase (ubiquinone) 1, subcomplex unknown, } 2 \text {, } \\
14.5 \mathrm{kDa}\end{array}$ & ENSP00000281031 & Down & 0.025489098 & $A D$ \\
\hline$A P L P 1$ & Amyloid beta (A4) precursor-like protein 1 & ENSP00000221891 & Up & 0.026382742 & $A D$ \\
\hline$B I R C 2$ & Baculoviral IAP repeat-containing 2 & ENSP00000227758 & Down & 0.026521867 & APO \\
\hline NDUFB5 & NADH dehydrogenase (ubiquinone) 1 beta subcomplex, 5, $16 \mathrm{kDa}$ & ENSP00000259037 & Down & 0.027921676 & $\mathrm{AD}$ \\
\hline PPARD & Peroxisome proliferator-activated receptor delta & ENSP00000310928 & Up & 0.029747209 & WNT \\
\hline SKP1 & S-phase kinase-associated protein 1 & ENSP00000231487 & Down & 0.03098415 & WNT \\
\hline PRKCB & Protein kinase $\mathrm{C}$, beta & ENSP00000305355 & Down & 0.031488508 & WNT \\
\hline CTNNBIP1 & Catenin, beta-interacting protein 1 & ENSP00000366466 & Down & 0.031553064 & WNT \\
\hline RCAN1 & Regulator of calcineurin 1 & ENSP00000320768 & Down & 0.031896183 & $A D$ \\
\hline AIFM1 & Apoptosis-inducing factor, mitochondrion-associated, 1 & ENSP00000287295 & Down & 0.031972517 & APO \\
\hline CALM2 & Calmodulin 2 (phosphorylase kinase, delta) & ENSP00000272298 & Down & 0.032263251 & $A D$ \\
\hline CAMK2D & Calcium/calmodulin-dependent protein kinase II delta & ENSP00000339740 & Up & 0.034576294 & WNT \\
\hline SMG7 & $\begin{array}{l}\text { Smg7 homolog, nonsense-mediated mRNA decay factor (Caenorhab- } \\
\text { ditis elegans) }\end{array}$ & ENSP00000340766 & Up & 0.034586995 & APO \\
\hline$T B L 1 X$ & Transducin (beta)-like 1X-linked & ENSP00000217964 & Up & 0.036511455 & WNT \\
\hline CASP3 & Caspase 3, apoptosis-related cysteine peptidase & ENSP00000311032 & Up & 0.037829198 & AD APO \\
\hline FRAT2 & Frequently rearranged in advanced T-cell lymphomas 2 & ENSP00000360058 & Up & 0.037835094 & WNT \\
\hline TCF7L2 & Transcription factor 7 -like 2 (T-cell specific, HMG-box) & ENSP00000358404 & Up & 0.03801246 & WNT \\
\hline PRICKLE1 & Prickle homolog 1 (Drosophila) & ENSP00000345064 & Up & 0.038401928 & WNT \\
\hline$M A P 3 K 1$ & Mitogen-activated protein kinase kinase kinase 1 & ENSP00000382423 & Up & 0.038406592 & $A D$ \\
\hline$M A M L 1$ & Mastermind-like 1 (Drosophila) & ENSP00000292599 & Up & 0.038709571 & NOT \\
\hline GRIN1 & Glutamate receptor, ionotropic, N-methyl D-aspartate & ENSP00000360616 & Up & 0.03916101 & $A D$ \\
\hline SNCA & Synuclein, alpha (non A4 component of amyloid precursor) & ENSP00000338345 & Down & 0.040205801 & $A D$ \\
\hline IKBKG & $\begin{array}{l}\text { Inhibitor of kappa light polypeptide gene enhancer in B cells, kinase } \\
\text { gamma }\end{array}$ & ENSP00000358622 & Down & 0.04087009 & $A P O$ \\
\hline$P R K C Z$ & Protein kinase $\mathrm{C}$, zeta & ENSP00000367830 & Down & 0.041055303 & WNT \\
\hline EP300 & MicroRNA 1281 & ENSP00000263253 & Up & 0.041373019 & NOT WNT \\
\hline ENDOG & Endonuclease G & ENSP00000361725 & Down & 0.042737537 & APO \\
\hline PPPЗСB & Protein phosphatase 3 (formerly 2B), catalytic subunit, beta isoform & ENSP00000378306 & Down & 0.046120071 & AD APO WNT \\
\hline$B C L 2 L 1$ & BCL2-like 1 & ENSP00000302564 & Up & 0.046646273 & APO \\
\hline NDUFV2 & NADH dehydrogenase (ubiquinone) flavoprotein 2, $24 \mathrm{kDa}$ & ENSP00000327268 & Down & 0.046908433 & $A D$ \\
\hline
\end{tabular}

Corrected $P$-values < 0.05 were considered significant. 'NOT', 'WNT', 'AD', and 'APO' represent NOTCH, WNT, Alzheimer's disease, and apoptosis subnetworks, respectively

anti-apoptotic effect, were also found together with significantly lower expression of presinilin 2 (PSEN2) and APBB1 (Table 1).

The in silico models were subsequently subjected to further analysis with the ViaComplex software that plots the expression mean values derived from each diseased sample (autism) over the expression of healthy control samples ( $z$ axis) in the network model (NOTCH, WNT, AD, and apoptosis), presenting them as two-dimensional (2D) ViaComplex-generated landscapes (Supplementary Figures S1B-S3B; and Figure 1b). The generated plot visualizes the general landscape of gene expression of diseased samples (autism) versus healthy controls for each subnetwork. Expression levels are color coded with warm colors (yellow to red) being indicative of increased expression, whereas cold (green to blue) colors indicate decreased gene expression when compared with control samples. The 2D ViaComplex plots revealed a general upregulation of $\mathrm{NOTCH}$ pathway (Supplementary Figure S1B) and specific decrease in the expression of mitochondria-related genes (network cluster on the upper left; Figure 1b).
NOWADA is an integrative network model for NOTCH, WNT, AD, and apoptosis subnetworks. As results presented above showed significant changes in expression of genes belonging to $\mathrm{NOTCH}, \mathrm{WNT}, \mathrm{AD}$, and apoptosis pathways in cerebellar brain biopsies from ASD patients, our next aim was to test the feasibility of an in silico model that is able to integrate these four subnetworks into one single network and therefore to characterize the relevant molecular route. The Venn diagram, which visualizes the level of subnetwork information integration (Figure 2), shows that the four subnetworks contain common nodes (genes/proteins) allowing communication with one another. Then, by using STRING 9.05 ('Experiments' and 'Databases'; confidence score of 0.600) and plotting with Cytoscape software, we developed a NOTCH-WNT-Alzheimer's Disease-Apoptosis (NOWADA) gene/protein interaction network model able to characterize in silico these molecular interactions (Figure 3 ). The model is composed of 374 genes/proteins interconnecting through 3665 interactions, with only five nodes (PPP3CA, $P P P 3 C B$, $P P P 3 C C, P P P 3 R 1$, and PSEN1) contributing to maximum 


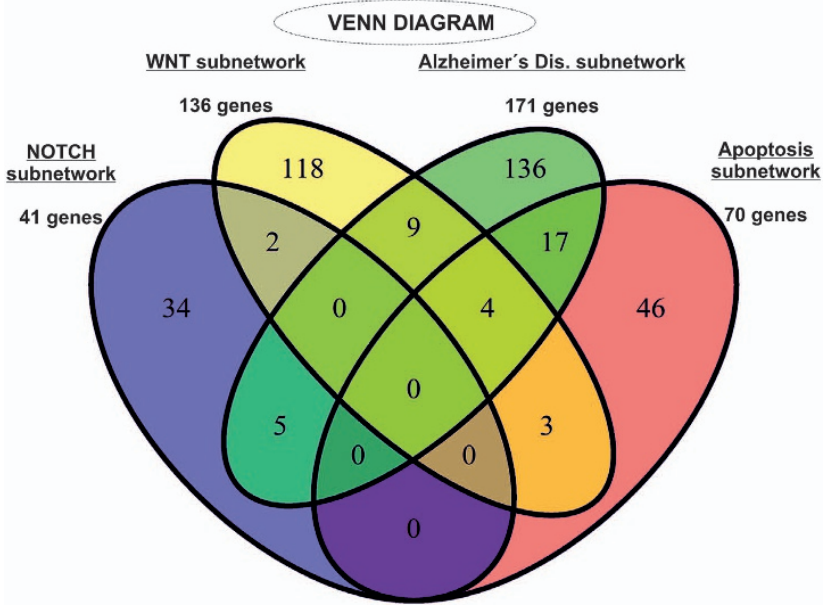

Figure 2 Venn diagram showing information integration from the studied subnetworks. NOTCH, WNT, AD, and apoptosis models contain common nodes (genes/proteins) with, at least, one subnetwork

three groups (NOTCH, WNT, AD, or apoptosis subnetworks) at the same time.

Identification of hey hub genes/proteins within NOWADA network in the context of autism. In order to describe the global characteristics of the network, we measured centralities ${ }^{18}$ or topological network properties as follows: (i) 'stress', representing how much a node (gene/ protein) is traversed by a high number of ideal routes or short paths in a network. Then, a gene/protein traversed by higher number of short paths will be, by definition, more stressed. (ii) 'connectivity or degree' that quantifies the local topology of each node by summing up the number of its adjacent nodes. (iii) 'Betweenness', which is similar to stress as a topological network property, provides a more informative and elaborated centrality index as it measures how frequently the shortest path, connecting every pair of nodes, is going through a third given node. In other words, both 'stress' and 'betweenness' give information about the influence of a node over the spread of information throughout the network. (iv) Finally 'closeness', defined by the inverse of the average length of the shortest paths to access all other proteins in the network, gives an idea about the level of proximity of a node to other nodes or how long it will take the information to spread from a given node to other nodes in the network. Logically, the larger the value, the faster the information spreads. Our focus in this part of the study is to target vulnerable (central) components in NOWADA network with $31 \%$ of its genes displaying significant changes in expression in the cerebellum of autistic patients (corrected $P$-values $<0.05)$. Upon calculation of each centrality value for each gene/protein (Supplementary Table S5), we identified the hub-bottlenecks (HBs) of the network that also displayed higher values of 'stress' and closeness centralities. These network nodes were (in alphabetical order) APP, CALM1, CASP3, CTNNB1, DVL2, DVL3, EP300, FZD5, GSK3B, MYC, NOTCH1, PLCB2, PRKCA, and TP53 (Supplementary Table S6 and Figure 4). As central members, these genes/ proteins will control the flow of biological information within the network and its disruption (e.g., by drug interaction) could destroy the entire network into small components. Remarkably, CTNNB1, gene encoding for $\beta$-catenin protein (Supplementary Table S2), was the node with top values for all the measured centralities (Supplementary Table S6 and Figure 4).

Systems pharmacology analysis of NOWADA network suggests $\mathrm{Mg}^{2+}$ and rapamycin as most efficient drugs to target the model in silico. Previous analysis allowed us to identify central nodes (bottlenecks) with high topological network values. At this stage, as NOWADA network can be considered as a common pathway model for AD and autism, these 14 nodes (genes/proteins) could represent potential targets for both pathologies in silico. With the aim of elucidating the most suitable and efficient drugs targeting the network in the context of autism, differential gene expression values were taken into account. Our selection criteria was then as follows: (i) to select drugs targeting higher number of genes/proteins within the network; (ii) from those, to choose the drugs affecting/associated to higher numbers of bottlenecks (preferably, HBs with high values of 'stress' and 'closeness' centralities); and (iii) to select drugs that targets, within the network (NOWADA), include higher number of genes with significant changes in expression. Upon systematic review of the literature (see Materials and Methods section), 47 used/proposed drugs for autism therapy were divided in 15 groups and tested for potential interaction/s with genes/proteins of the network model. The groups are acetylcholinesterase inhibitors, allosteric modulators of metabotropic glutamate receptors, antidepressants (SSRI and tricyclic), antiepileptics/anticonvulsants, antiopioids, antipsychotics, complementary and alternative medicines, inhibitors of mTOR, neurohormones, NMDAR (agonists and antagonists), mood stabilizers, psycoestimulants, and sympatholytic medications. Incidentally, 36 out of the 47 autism-related drugs have already been studied in different models of $A D$ (in humans or in vivo) for potential therapeutic use ${ }^{19-22}$ (Supplementary Table S7). Upon using STITCH 3.1, we confirmed that 16 out of the 47 tested drugs had positive hits with at least one gene/protein of NOWADA network (with 'Experiments' and 'Databases' as input options; confidence score of 0.600). These therapeutic agents were (in alphabetical order) as follows: chlorpromazine, clozapine, D-cycloserine, fluoxetine, galantamine, haloperidol, imipramine, lithium, luteolin, $\mathrm{Mg}^{2+}$, melatonin, memantine, olanzapine, rapamycin, valproic acid, and ziprasidone. Most targeted nodes were GSK3B (glycogen synthase kinase $3 \beta, 6$ hits), AKT1 (5 hits), CALM1 (3 hits), GRIN1 (3 hits), GRIN2B (3 hits), CHRNA7 (2 hits), GRIN2A (2 hits), and JUN (2 hits) (Supplementary Table S9). Except for CHRNA7, our systematic review of the literature could confirm the expression of the indicated gene products in neuronal and/or glial cells (astroglia, microglia, and oligodendroglia; Supplementary Table S9), thus representing both neuronal and glial targets. When looking into the characteristics of the tested compounds/drugs-genes/protein interactions, $\mathrm{Mg}^{2+}$ and rapamycin are highlighted as the most efficient drugs in silico to target this disrupted pathway, which is here represented in silico by NOWADA network 


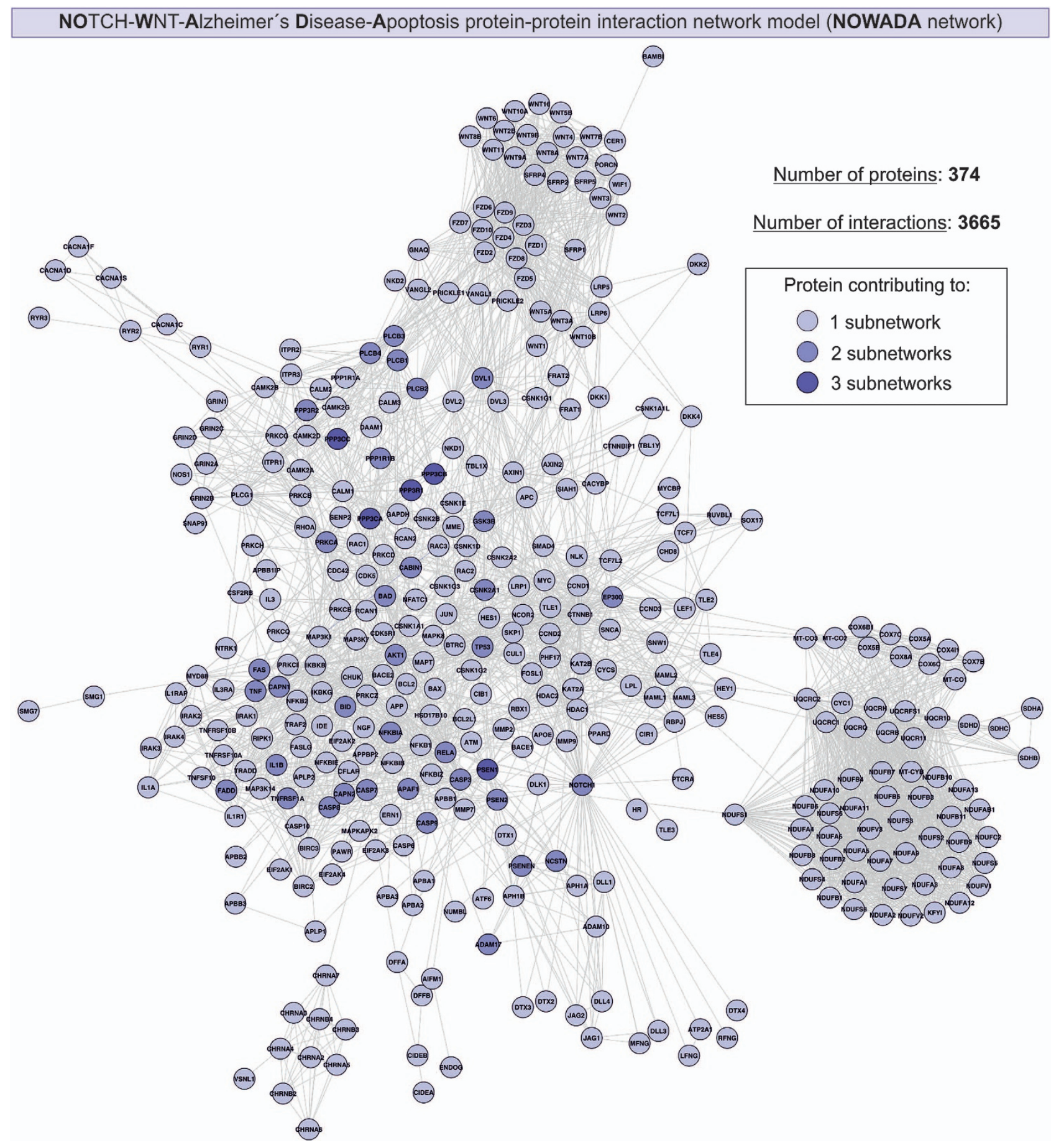

Figure 3 Network model of interactions between genes/protein belonging to NOTCH, WNT, AD, and apoptosis subnetworks (NOWADA network). The present model was developed by using the STRING 9.05 database resource search tool, under a confidence score of 0.600 , and by using 'Databases' and 'Experiments' as input options and visualized by plotting it with Cytoscape software. The number of subnetwork contributions of each gene/protein within the network is represented in the figure as indicated in the inset

(Supplementary Table S10). More specifically, $\mathrm{Mg}^{2+}$ interacts with 32 genes/proteins; among those, eight differentially expressed genes in the cerebellum of autistic patients: the upregulated EIF2AK2 (corrected $P$-value $=0.002850857)$ and CAMK2D (corrected $P$-value $=$ $0.034576294)$, as well as the downregulated $C D C 42$ (corrected $P$-value $=0.002000135), \quad$ COX5A (corrected $P$-value $=0.003530677), \quad$ NDUFV1 (corrected $P$-value $=$ 0.011017543 ), NDUFS8 (corrected $P$-value $=0.014197263$ ), RAC3 (corrected $P$-value $=0.014704894$ ), and CALM2 (corrected $P$-value $=0.032263251$ ) (Figure 5 ). In order to elucidate the biological processes that $\mathrm{Mg}^{2+}$ could be 

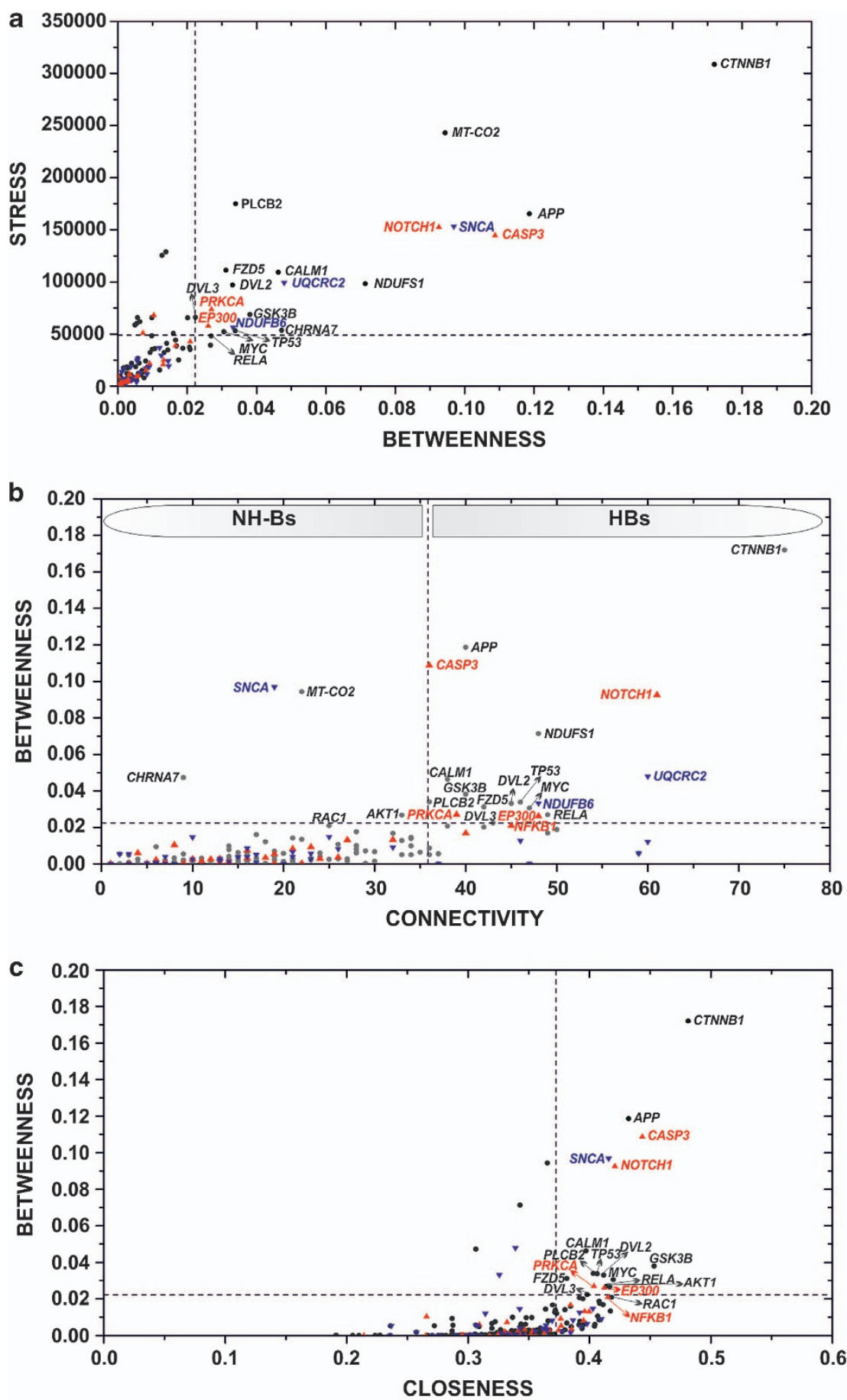

Gene

$\Delta$ Upregulated gene

Downregulated gene

Figure 4 Analysis of the topological properties $(\mathbf{a}-\mathbf{c})$ of genes/proteins belonging to the network (NOWADA). Dashed lines are indicating the threshold value for each property. Upregulated and downregulated genes in the subnetwork are marked with red and blue triangles, respectively, as indicated in the inset. Note that NH-Bs and HBs distinguish non-HBs from HBs, respectively

influencing in this context, a functional enrichment analysis of the genes belonging to the $\mathrm{Mg}^{2+}$ subnetwork was performed. The top 10 affected processes are as follows: phosphorylation, phosphorus metabolic process or phosphate-containing compound metabolic process, neuromuscular process, regulation of neurological system process, protein amino-acid autophosphorylation, small GTPase-mediated signal transduction, mitochondrial electron transport (NADH to ubiquinone), positive regulation of cell projection organization, and intracellular 


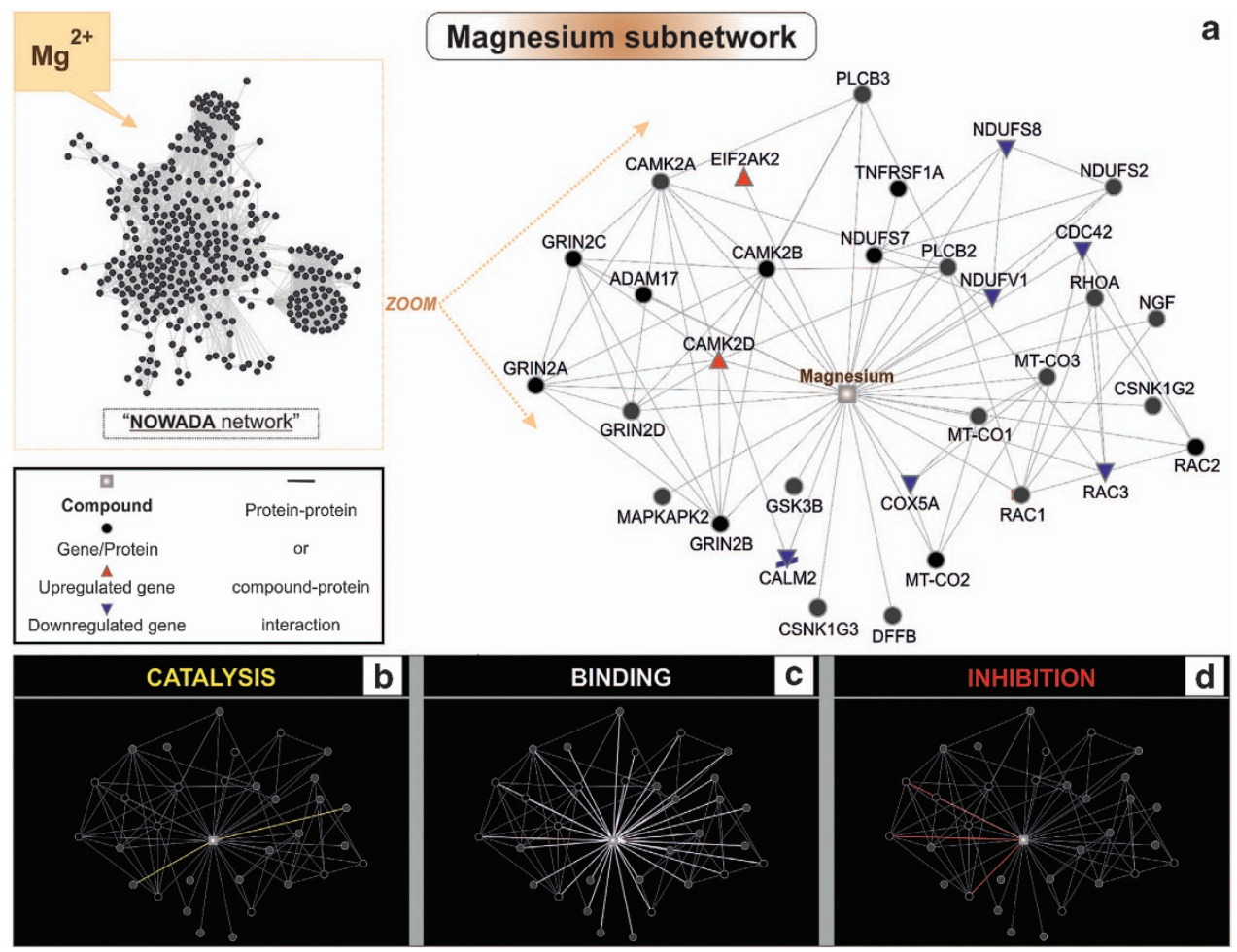

Figure $5 \mathrm{Mg}^{2+}$ subnetwork analysis. (a) In silico network model of the interactions between $\mathrm{Mg}^{2+}$ and genes/proteins belonging to the network (NOWADA), developed by using STITCH 3.1 with 'Experiments' and 'Databases' as input options and a confidence score of 0.600 . (b) Actions view representation between the network nodes by 'catalysis' (yellow). (c) Actions view representation between the network nodes by 'binding' (white color). (d) Actions view representation between the network nodes by 'inhibition' (red color). Upregulated and downregulated genes in the subnetwork are marked with red and blue triangles, respectively, as indicated in the inset

signaling cascade (corrected $P$-value $<0.05$; Supplementary Table S11).

\section{Discussion}

Here we studied the possible neurobiological mechanism involved in the excessive rates of early brain overgrowth observed in autism ${ }^{4}$ based on the recent evidence, indicating a possible role for the AD-associated APP processing pathway in ASD. ${ }^{23}$ Proliferation in the brain results from balancing proliferative rates and developmental apoptosis (i.e., more proliferation and less death will result in a larger brain). ${ }^{24}$ APP is proteolytically processed by two competing pathways such as the amyloidogenic ( $\beta$-secretase-mediated) and the non-amyloidogenic ( $\alpha$-secretase-mediated) pathways. ${ }^{25}$ sAPP $\beta$ (secreted APP $\beta$ ) and the neurotoxic $A \beta$ peptide are generated from APP and released to the extracellular site by proteolytic cleavage of both $\beta$ - and $\gamma$-secretases. ${ }^{26} \mathrm{~A} \beta$ has been suggested to have a critical role in neurotoxicity and apoptotic events seen in $A D .{ }^{27}$ In contrast, the non-amyloidogenic product SAPP $\alpha$ and the p3 peptide are formed by proteolytic cleavage of both $\alpha$ - and $\gamma$-secretases ${ }^{26}$ SAPP $\alpha$ exerts proliferative effects on neural progenitor cells isolated from embryonic brains and is able to enhance synaptogenesis, neurite outgrowth, cell survival, and cell adhesion; ${ }^{28-31}$ and APP seems to be able to modulate the neuronal precursors migration. ${ }^{32}$ As $\gamma$-secretase cleaves several proteins that include APP and Notch, ${ }^{33}$ the potential role of NOTCH signaling pathway in the genesis of $A D$ is also considered. ${ }^{34}$ Focused microarray analysis used in this study demonstrated that expression of $40 \%$ of the AD-related genes was altered in the cerebellum of autistic patients (corrected $P$-value $<0.05)$, these changes mainly represented by downregulation of NADH dehydrogenases and cytochrome $c$ oxidases (Table 1). These results reflect deficient mitochondrial respiratory chain that is consistent with recent reports describing mitochondrial dysfunction in ASD; ${ }^{35}$ or may indirectly confirm tight Notch-mitochondria interconnections. $^{36}$ An upregulation of GRIN1 (corrected $P$-value $=0.03916101)$, the channel-forming subunit NR1 of NMDA glutamate receptors and MAP3K1 (corrected $P$-value $=0.038406592$ ), also known as MEKK1 or MAPK/ ERK Kinase Kinase 1, which activates JNK and ERK pathways with anti-apoptotic effect, ${ }^{37}$ were also found among the AD-related genes in ASD samples (Table 1). In vivo studies have shown that stressful events during gestation can increase the expression of NMDA receptors in the brain. ${ }^{38}$ The altered expression of NMDA receptors may be related to epigenetic regulation (e.g., DNA hypomethylation) because histone lysine methylation at gene promoters is involved in developmental regulation and maintenance of region-specific expression patterns of ionotropic and metabotropic glutamate receptors in the brain. ${ }^{39}$ Furthermore, glutamate receptors expression and/or their activity can modulate the APP processing mechanisms. ${ }^{40}$ High glutamate receptors activation and consequent increase in intracellular calcium activate the ERK signaling cascade, enhancing $\alpha$-secretase cleavage 
of APP, and thus reducing APP processing into $\mathrm{A} \beta$. An increase in $\alpha$-secretase activity may lead to higher production of SAPP $\alpha .{ }^{26}$ In this study, we hypothesize that deregulated glutamatergic synaptic transmission/plasticity, caused by increased expression of GRIN1 and hence increased density of NMDA receptors, may affect neuronal growth in autism by shifting APP processing to the production of $\operatorname{SAPP} \alpha$ through ERK-mediated $\alpha$-secretase activity. SAPP $\alpha$, in turn, may facilitate proliferation by activating the PI3K/Akt/mTOR pathway. ${ }^{41,42}$ Based on the present data and existing literature, we proposed this model (Figure 6) as a mechanism that could explain the focal modification of neurogenesis, migration, and alterations of the cytoarchitecture of brain cortex, subcortical structures and cerebellum observed in individuals with autism. ${ }^{43}$ Consequently, the decrease in expression of mitochondrial enzymes observed in our array (Table 1) may

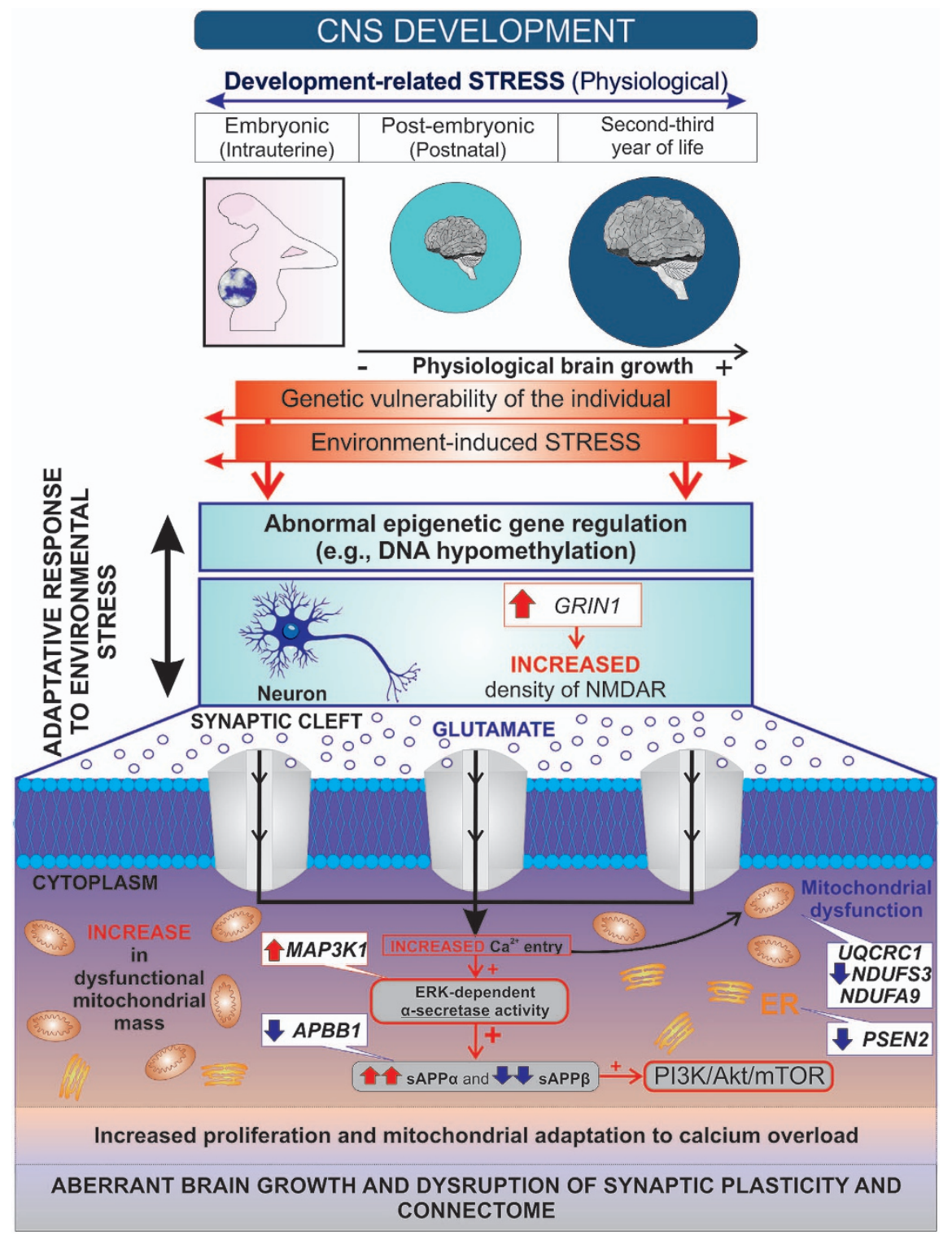

Figure 6 Hypothetical model of the synaptic mechanism regulating A $\beta$ production and the link to aberrant brain growth and connectivity in autism. The development of living organisms parallels to a so-called physiological 'intrinsic developmental stress', which is associated to massive internal changes during morphogenesis, and thus contributes to the time window of vulnerability to the environment. Development and severity of ASD are likely to arise from complex interactions between pre-existing genetic vulnerability/ies in these children, the exposure to noxious environmental factors, and the timing of the stressful event(s); given that prenatal life, infancy, childhood, and adolescence are critical periods characterized by increased vulnerability to stressors. ${ }^{2,3}$ Glial activation and neuroinflammation seem to persist during adulthood in autism, and early brain overgrowth in autism could be a consequence of an over-activation of neural proliferation in a trial to compensate the cellular loss induced by environmental stress/ ors, triggering precipitous/uncontrolled migration and misdistribution of neurons among different brain areas. Our model proposed that aberrant epigenetic regulation may lead to increased density of NMDA receptors and, therefore, to increased $\mathrm{Ca}^{+2}$ entry and stimulation of ERK-dependent $\alpha$-secretase activity. The decrease in mitochondrial enzymatic activity together with the downregulation of PSEN2 at the ER may represent a compensatory mechanism to reduce the $\mathrm{Ca}^{2+}$ overload-induced apoptosis. PSEN2 downregulation may diminish the interaction between ER and mitochondria, reducing its $\mathrm{Ca}^{+2}$ uptake. In turn, mitochondrial mass would increase most likely to maintain the cellular ATP levels. Higher levels of SAPP $\alpha$ would activate the PI3K/Akt/mTOR pathway resulting in proliferation, aberrant brain growth, and disruption of synaptic plasticity and connectome 
represent a compensatory mechanism to contain $\mathrm{Ca}^{2+}$ overload-induced apoptosis in these cells. It has already been reported that compromised mitochondria accumulate (observed by increased mitochondrial mass) in pyramidal neurons in temporal cortex of younger ASD subjects. ${ }^{44}$ Moreover, PSEN1 and PSEN2 are believed to have almost overlapping cellular functions and contribute to diverse physiological processes, such as regulation of $\mathrm{Ca}^{2+}$ homeostasis, protein transport and turnover, autophagy, cell adhesion, neurotransmitter release, and axon guidance. ${ }^{45}$ PSEN2, however, seems to be responsible for endoplasmic reticulum (ER) and mitochondria interactions. ${ }^{46}$ Closer ERmitochondria juxtaposition (regulated by PSEN2) may expose mitochondria to excessive $\mathrm{Ca}^{2+}$ stimulation, triggering the apoptotic cascade by mitochondria $\mathrm{Ca}^{2+}$ overload. In our array analysis, we found that PSEN2 is downregulated (corrected $P$-value $=0.005968353$ ) in the cerebellum of autistic patients (Table 1), which could represent another compensatory mechanism to reduce $\mathrm{Ca}^{2+}$ overload-induced apoptosis. Our hypothesis is further supported by the following observations: (i) mutant mice in which glutamate receptors are overstimulated by knocking out $(\mathrm{KO})$ glutamate transporters GLAST and GLT1, and thus leading to excessive glutamatergic signaling in the prenatal stage, compromising early brain development via overstimulation of NMDARs. NR1 deletion in double $\mathrm{KO}$ mice almost completely rescued multiple brain defects including cortical, hippocampal, and olfactory bulb disorganization and defective corticothalamic and thalamocortical axonal projections; ${ }^{47}$ (ii) opposite to what it is seen in AD patients, higher levels of SAPP $\alpha$ have been described in plasma from autistic children when compared with controls, favoring an increased $\alpha$-secretase pathway; ${ }^{12,48}$ (iii) evidence of autoimmunity and persistent systemic immune activation have been reported in $A S D,{ }^{49}$ and mice overexpressing human SAPP $\alpha$ indeed exhibit higher T-cell cytokine secretion together with reduced $\mathrm{CD}^{+}{ }^{+}$and higher $\mathrm{CD} 8^{+} \mathrm{T}$-cell populations in splenocytes when compared with wild-type animals. These animals also display hypoactivity, impaired social interaction, elevated levels of brain glial fibrillary acidic protein (GFAP) expression, and altered Notch1 and interleukin6 levels. $^{50}$ In the brain of autistic individuals, increased expression of GFAP in the areas with disturbed neuronal architecture has been detected together with interleukin-6, interleukin-8, tumor necrosis factor- $\alpha$, interferon- $\gamma$, and granulocyte-macrophage colony-stimulating factor, suggesting astrogliotic response and potential alterations in neurogenesis and neuronal migration. ${ }^{51-54}$ (iv) Finally, we observed a significant decrease (corrected $P$-value $=0.024237411$ ) in expression of $A P B B 1$ (A $\beta$ A4 precursor protein binding, family $B$, member 1; or F65) (Table 1). In vitro $\mathrm{F} 65$ overexpression induces a marked increase in $\mathrm{A} \beta$ secretion, whereas $\mathrm{A} \beta$ secretion is decreased in Fe65 knockdown cells and also in hippocampal neurons of Fe65/Fe65L1 KO mice. ${ }^{55-57}$

Systems pharmacology analyses of NOWADA network revealed that $\mathrm{Mg}^{2+}$ and rapamycin could efficiently target this pathway in silico, when compared to other drugs (Supplementary Table S10). RhoGAPs, regulatory molecules of RHO GTPases (e.g., CDC42, RHOA, and RAC1), which altered expression were shown in autism, ${ }^{3}$ use $\mathrm{Mg}^{2+}$ as a cofactor to reach catalytic efficiency and specificity in
GTP hydrolysis (Supplementary Table S11). ${ }^{58}$ Furthermore, GSK3B, a HB in our network model (Supplementary Table S6), is a ubiquitous serine/threonine kinase that catalyzes the transfer of $\gamma$-phosphate of ATP to the hydroxyl oxygen of the Ser and Thr residues of a kinase-specific protein substrate is a $\mathrm{Mg}^{2+}$-dependent kinase. ${ }^{59}$ Its aberrant function has been linked to diverse neurological disorders such as AD. ${ }^{60}$ Lower concentrations of $\mathrm{Mg}^{2+}$ were described in children with autism. ${ }^{61}$ Similarly, in $\mathrm{AD}$ patients, $\mathrm{Mg}^{2+}$ concentrations in the brain seem to be significantly lower when compared with age-matched normal individuals. ${ }^{62}$ Recently, it was suggested that elevation of brain $\mathrm{Mg}^{2+}$ concentration in the brain exerts substantial synaptoprotective effects in an in vivo model of $\mathrm{AD}$, and hence $\mathrm{Mg}^{2+}$ may have therapeutic potential for treating $A D$ in humans. ${ }^{17}$ In autism, positive behavioral effects of combined $\mathrm{Mg}^{2+}$ and pyridoxine treatment were described; ${ }^{63}$ combination that was also proposed to be beneficial in ASD patients that experience seizures. ${ }^{64}$ The therapeutic usage of rapamycin (mTOR inhibitor) in ASD is nowadays discussed. TSC1 and TSC2 are upstream inhibitory regulators of mTOR activity, and studies performed in $\mathrm{TSC}^{+1-}$ mice showed that treatment with rapamycin can rescue synaptic plasticity and reverse the abnormal late phase of long-term potentiation. ${ }^{20}$ These results encourage future clinical trials with TOR inhibitors as pharmacological treatment of ASD.

We believe that the computational analyses performed in this study gave valuable clues to (i) develop a model that may explain the aberrant brain overgrowth and impaired neuronal connectivity observed in these children; and (ii) refer to the need of further therapeutic exploration of $\mathrm{Mg}^{2+}$ - and rapamycin-based treatments in animal models and clinical trials with autistic patients.

\section{Materials and Methods}

Development of gene/protein network models. NOTCH, WNT, AD, and apoptosis subnetwork models were developed through (i) extracting the information provided by the KEGG PATHWAY database (http://www.genome.jp/ kegg/pathway.html; NOTCH pathway: map04330, WNT pathway: map 04310; AD pathway: map05010, and apoptosis pathway: map04210); and (ii) by establishing the interactions between genes/proteins with the database resource Search Tool for the Retrieval of Interacting Genes/Proteins STRING version 9.05 (http://string-db.org/); with 'Experiments' and 'Databases' as input options and a confidence score of 0.600 . STRING is a well-known public database with information about direct and indirect functional protein-protein interactions. The genes/proteins belonging to NOTCH, WNT, AD, and apoptosis subnetwork models were identified by the HUGO Gene Symbol ${ }^{65}$ and Ensemble protein ID (Supplementary Tables S1-S4). Once they were selected, the links between two different nodes (genes/proteins), provided by the STRING database, are saved in data files to be processed in the Medusa interface ${ }^{66}$ and visualized as a subnetwork (NOTCH, WNT, AD, or apoptosis). The Venn diagram was constructed by using the freely available software system R (http://www. r-project.org) ${ }^{67}$ in order to visualize the grade of molecular relation (common genes/proteins) between the generated subnetworks. The in silico network model integrating NOTCH, WNT, AD, and apoptosis subnetworks (NOWADA) was developed by using again STRING version 9.05 with 'Experiments' and 'Databases' as input options and a confidence score of 0.600 (0.400 is considered 'medium confidence') and plotted by using Cytoscape, an open source platform for complex network analysis and visualization (http://www.cytoscape.org/). ${ }^{68}$

Data acquisition and processing, determination of variably expressed genes, statistics, and gene expression network visualization. Microarray data (raw data;.cel files) were obtained from the 
Geo DataSets database (http://www.ncbi.nlm.nih.gov/geo/). The data set (GSE38322), originally contributed by Ginsberg et al., ${ }^{69}$ is publicly available; it contains data from cerebellar brain tissue of autistic patients and control subjects. Experimental assays are described in full in the original publication and details include the selection criteria of patients (both inclusion and exclusion criteria) and diagnostic profile. ${ }^{69}$ For elucidating the differential expression of members from the $\mathrm{NOTCH}, \mathrm{WNT}, \mathrm{AD}$, and apoptosis subnetworks, expression data were filtered from probes with $<0.05$ signal detection $P$-values and normalized by using the lumi package from $R$ and robust spline normalization. For differential gene expression analysis, normalized data of cerebellar samples from patients versus controls were analyzed by using the limma package from $R^{67}$ and false discovery rate (FDR) control for statistical assessment of the microarray data (corrected $P$-values $<0.05$ were considered significant). Specific corrected $P$-values for each differentially expressed gene are provided (Table 1). In order to visualize the

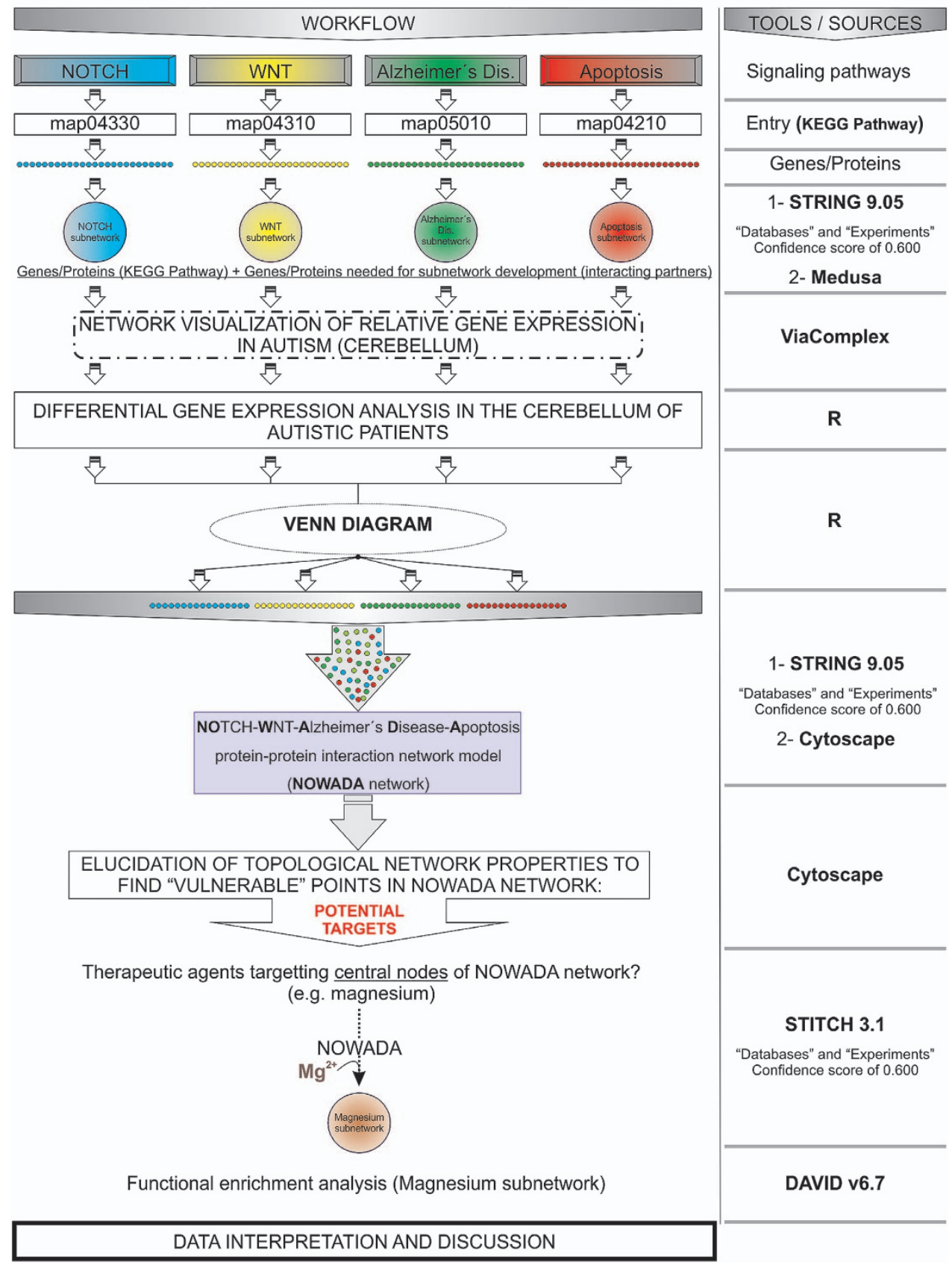

Figure 7 Abstract workflow summarizing the different approaches used for the present study. The information from the different pathways (NOTCH, WNT, AD, and apoptosis) was gathered from KEGG pathway (http://www.genome.jp/kegg/pathway.html) to develop the subnetworks. The differential expression of the genes belonging to each subnetwork was analyzed in the cerebellum of autistic patients by using R. A Venn diagram showed common genes/proteins between NOTCH, WNT, AD, and apoptosis pathways. Thereafter, a network model was developed for integrating these subnetworks into one single gene/protein interaction network model (NOWADA network) by using STRING 9.05 and Cytoscape tools. Further elucidation of the topological network properties revealed a number of potential molecular targets or 'vulnerable' points of the in silico model and therapeutic agents used in autism targeting central nodes of the network were studied (STITCH 3.1). Finally, a subnetwork representing the interaction between $\mathrm{Mg}^{2+}$ and genes/proteins from NOWADA network was constructed and a functional enrichment analysis was performed (DAVID v6.7) to elucidate the biological processes potentially affected by this compound 
general landscape of gene expression in silico, gene expression in samples from autism were plotted versus the expression found in healthy controls to be visualized with the ViaComplex software, a tool that was previously developed and validated in our laboratory. ${ }^{70}$ This software plots gene expression over the Medusa network (in a color scale) by overlapping functional input data (microarray expression data) with interaction information (NOTCH, WNT, AD, and apoptosis subnetworks) and distributes the microarray signal according to the coordinates of the nodes and its interactions in the network of interest.

Elucidation of network centralities to predict the relevance of genes in the overall network architecture. Topological network properties of the genes/proteins integrating the network (NOWADA) were calculated by using Cytoscape ${ }^{68}$ Numeric values corresponding to the properties of each node are additionally provided (Supplementary Table S5). Thresholds for selection criteria of the most relevant nodes according to their centrality values were established considering one s.d. of the mean for each topological network properties: 'stress': 48919.44 (mean $=15251.9$ ); 'connectivity or degree': 35.84815 (mean = 19.59893); 'betweenness': 0.022270086 (mean $=0.005765439$ ); and 'closeness': 0.372488254 (mean $=0.325097663$ ). Centrality values were plotted in graphs by using OriginLab (http://www.originlab.com/index.aspx?go= Products/OriginPro). Nodes (genes/proteins) with high connectivity (above the threshold) and low betweenness centrality (below the threshold) are considered hub-non-bottlenecks and those ones with a value above the thresholds for both connectivity and betweenness centrality are referred to as HBs. Similarly, non-HBs (NH-Bs) are nodes with low connectivity and high betweenness centrality, and non-hub-non-bottlenecks are nodes with both connectivity and betweenness centrality values below the thresholds. ${ }^{18}$

In silico development of compound (drug)-gene/protein network model. To construct the compound (drug)-gene/protein network models, we first performed a systematic review of relevant literature associated with autism or AD therapy in the PubMed database (http://www.ncbi.nlm.nih.gov/ pubmed/). These articles were obtained by using the two terms 'autism' and 'ASD' and combining them with the following terms: 'Alzheimer's disease', 'therapy', 'therapeutics', 'treatment', and/or 'drug', respectively. Moreover, compound identifier, formula, description, and selected autism- and AD-related reports (with PMID) for these drugs (Supplementary Table S6) are additionally provided with KEGG DRUG (http://www.genome.jp/kegg/drug/), the Search Tool for Interactions of Chemicals STITCH version 3.1 (http://stitch.embl.de/), and PubMed database as sources of information. Second, these drugs were submitted to in silico analysis by searching the number of genes/proteins within NOWADA network that are targeted by the selected drugs. To achieve this goal, STITCH version 3.1 (http:// stitch.embl.de/) was used with 'Experiments' and 'Databases' as input options and a confidence score of 0.600 ( 0.400 is considered 'medium confidence'). A list with the most drug-targeted network nodes (genes/proteins) is also provided (Supplementary Table S8). Again, the links between two different nodes (drug-genes/proteins), provided by the STITCH database, is saved in data files to be handled in the Medusa interface and visualized as a subnetwork. For screening potential cellular targets of the most drug-targeted network nodes (NOWADA), another systematic review of both original research articles and reviews was performed in PubMed database. These articles were obtained by using the genes/proteins name or symbol and combining them with the following terms: 'Neuronal', 'Neuron', 'Astroglia', 'Astrocyte', 'Microglia', 'Oligodendroglia', and/or 'Oligodendrocyte' (Supplementary Table S9).The selected references confirm the expression of the indicated gene products in brain cells. Note that the selected references do not cover therapeutic modalities, age or brain region specificity.

Functional enrichment analysis (biological processes). The biological processes of the genes products belonging to the subnetwork model of interactions was determined by using the database for annotation, visualization, and integrated discovery DAVID v6.7 (http://david.abcc.ncifcrf. gov/), giving a number of functional annotation tools to researchers for better comprehension of the biological meaning behind any large list of genes. Only those biological processes with corrected $P$-value $<0.05$ (FDR) were selected. Specific corrected $P$-values for each biological process are provided (Supplementary Table S9).

A graphical abstract, summarizing the contents and the methodological approaches used for the present study, is also provided (Figure 7).

\section{Conflict of Interest}

The authors declare no conflict of interest.

Acknowledgements. First of all, our sincere apologies to the authors whose work have not been cited in the present study because of space considerations. We thank Brazilian research funding agencies FAPERGS (PqG 1008860, PqG 1008857, ARD11/1893-7, and PRONEX 1000274), CAPES (PROCAD 066/2007), CNPq (558289/2008-8 and 302330/2009-7), as well as PROPESQ-UFRGS for supporting this work.

1. Casanova MF. The neuropathology of autism. Brain Pathol 2007; 17: 422-423.

2. Zeidán-Chuliá $F$, Gursoy UK, Könönen $E$, Gottfried $C$. A dental look at the autistic patient through orofacial pain. Acta Odontol Scand 2011; 69: 193-200.

3. Zeidán-Chuliá F, Rybarczyk-Filho JL, Salmina AB, de Oliveira BH, Noda M, Moreira JC. Exploring the multifactorial nature of autism through computational systems biology: calcium and the Rho GTPase RAC1 under the spotlight. Neuromolecular Med 2013; 15 : 364-383.

4. Courchesne $E$, Carper R, Akshoomoff N. Evidence of brain overgrowth in the first year of life in autism. JAMA 2003; 290: 337-344.

5. Miyazaki K, Narita N, Sakuta R, Miyahara T, Naruse H, Okado N et al. Serum neurotrophin concentrations in autism and mental retardation: a pilot study. Brain Dev 2004; 26 : 292-295.

6. Mills JL, Hediger ML, Molloy CA, Chrousos GP, Manning-Courtney P, Yu KF et al. Elevated levels of growth-related hormones in autism and autism spectrum disorder. Clin Endocrinol (Oxf) 2007; 67: 230-237.

7. Ricci S, Businaro R, Ippoliti F, Lo Vasco VR, Massoni F, Onofri E et al. Altered cytokine and BDNF levels in autism spectrum disorder. Neurotox Res 2013; 24: 491-501.

8. Zeidán-Chuliá F, Salmina AB, Malinovskaya NA, Noda M, Verkhratsky A, Moreira JC. The glial perspective of autism spectrum disorders. Neurosci Biobehav Rev 2014; 38 : 160-172.

9. Braak H, de Vos RA, Jansen EN, Bratzke H, Braak E. Neuropathological hallmarks of Alzheimer's and Parkinson's diseases. Prog Brain Res 1998; 117: 267-285.

10. Selkoe DJ. Alzheimer's disease: genes, proteins, and therapy. Physiol Rev 2001; 81: $741-766$.

11. Rodríguez JJ, Verkhratsky A. Neurogenesis in Alzheimer's disease. J Anat 2011; 219: 78-89.

12. Ray B, Long JM, Sokol DK, Lahiri DK. Increased secreted amyloid precursor protein- $\alpha$ $(\mathrm{SAPP} \alpha)$ in severe autism: proposal of a specific, anabolic pathway and putative biomarker. PLoS One 2011; 6: e20405.

13. Courchesne E, Redcay E, Morgan JT, Kennedy DP. Autism at the beginning: microstructural and growth abnormalities underlying the cognitive and behavioral phenotype of autism. Dev Psychopathol 2005; 17: 577-597.

14. Reeber SL, Otis TS, Sillitoe RV. New roles for the cerebellum in health and disease. Front Syst Neurosci 2013; 7: 83.

15. Rogers TD, McKimm E, Dickson PE, Goldowitz D, Blaha CD, Mittleman G. Is autism a disease of the cerebellum? An integration of clinical and pre-clinical research. Front Syst Neurosci 2013; 7: 15.

16. Cai Z, Zhao B, Li K, Zhang L, Li C, Quazi SH et al. Mammalian target of rapamycin: a valid therapeutic target through the autophagy pathway for Alzheimer's disease? J Neurosci Res 2012; 90: 1105-1118.

17. Li W, Yu J, Liu Y, Huang $X$, Abumaria N, Zhu $Y$ et al. Elevation of brain magnesium prevents and reverses cognitive deficits and synaptic loss in Alzheimer's disease mouse model. J Neurosci 2013; 33: 8423-8441.

18. Rosado JO, Henriques JP, Bonatto D. A systems pharmacology analysis of major chemotherapy combination regimens used in gastric cancer treatment: Predicting potential new protein targets and drugs. Curr Cancer Drug Targets 2011; 11: 849-869.

19. Kerbeshian J, Burd L, Fisher W. Lithium carbonate in the treatment of two patients with infantile autism and atypical bipolar symptomatology. J Clin Psychopharmacol 1987; 7: 401-405.

20. Ehninger D, Han S, Shilyansky C, Zhou Y, Li W, Kwiatkowski DJ et al. Reversal of learning deficits in a Tsc2 +/- mouse model of tuberous sclerosis. Nat Med 2008; 14: 843-848.

21. Spilman P, Podlutskaya N, Hart MJ, Debnath J, Gorostiza O, Bredesen D et al. Inhibition of mTOR by rapamycin abolishes cognitive deficits and reduces amyloid-beta levels in a mouse model of Alzheimer's disease. PLoS One 2010; 5: e9979.

22. Nunes MA, Viel TA, Buck HS. Microdose lithium treatment stabilized cognitive impairment in patients with Alzheimer's disease. Curr Alzheimer Res 2013; 10: 104-107.

23. Lahiri DK, Sokol DK, Erickson C, Ray B, Ho CY, Maloney B. Autism as early neurodevelopmental disorder: evidence for an $\operatorname{SAPP} \alpha$-mediated anabolic pathway. Front Cell Neurosci 2013; 7: 94.

24. Raff MC, Barres BA, Burne JF, Coles HS, Ishizaki Y, Jacobson MD. Programmed cell death and the control of cell survival: lessons from the nervous system. Science 1993; 262: $695-700$. 
25. Zhang $\mathrm{H}, \mathrm{Ma} \mathrm{Q}$, Zhang $\mathrm{YW}, \mathrm{Xu} \mathrm{H}$. Proteolytic processing of Alzheimer's $\beta$-amyloid precursor protein. J Neurochem 2012; 120(Suppl 1): 9-21.

26. Kojro E, Postina R. Regulated proteolysis of RAGE and AbetaPP as possible link between type 2 diabetes mellitus and Alzheimer's disease. J Alzheimers Dis 2009; 16 : 865-878.

27. Yu W, Mechawar N, Krantic S, Quirion R. Evidence for the involvement of apoptosisinducing factor-mediated caspase-independent neuronal death in Alzheimer disease. Am J Pathol 2010; 176: 2209-2218.

28. Mattson MP. Cellular actions of beta-amyloid precursor protein and its soluble and fibrillogenic derivatives. Physiol Rev 1997; 77: 1081-1132.

29. Ohsawa I, Takamura C, Morimoto T, Ishiguro M, Kohsaka S. Amino-terminal region of secreted form of amyloid precursor protein stimulates proliferation of neural stem cells. Eur J Neurosci 1999; 11: 1907-1913

30. Caillé I, Allinquant B, Dupont E, Bouillot C, Langer A, Müller U et al. Soluble form of amyloid precursor protein regulates proliferation of progenitors in the adult subventricular zone. Development 2004; 131: 2173-2181.

31. Gakhar-Koppole N, Hundeshagen P, Mandl C, Weyer SW, Allinquant B, Müller U et al. Activity requires soluble amyloid precursor protein alpha to promote neurite outgrowth in neural stem cell-derived neurons via activation of the MAPK pathway. Eur J Neurosci 2008 28: 871-882.

32. Young-Pearse TL, Bai J, Chang R, Zheng JB, LoTurco JJ, Selkoe DJ. A critical function fo beta-amyloid precursor protein in neuronal migration revealed by in utero RNA interference. J Neurosci 2007; 27: 14459-1469.

33. Boo JH, Sohn JH, Kim JH, Song H, Mook-Jung I. Rac1 changes the substrate specificity of gamma-secretase between amyloid precursor protein and Notch1. Biochem Biophys Res Commun 2008; 372: 913-917.

34. Woo HN, Park JS, Gwon AR, Arumugam TV, Jo DG. Alzheimer's disease and Notch signaling. Biochem Biophys Res Commun 2009; 390: 1093-1097.

35. Guevara-Campos J, González-Guevara L, Puig-Alcaraz C, Cauli O. Autism spectrum disorders associated to a deficiency of the enzymes of the mitochondrial respiratory chain Metab Brain Dis 2013; 28: 605-612.

36. Lee SF, Srinivasan B, Sephton CF, Dries DR, Wang B, Dewey CM et al Gamma-secretase-regulated proteolysis of the Notch receptor by mitochondrial intermediate peptidase. J Biol Chem 2011; 286: 27447-27453.

37. Yujiri T, Sather S, Fanger GR, Johnson GL. Role of MEKK1 in cell survival and activation of JNK and ERK pathways defined by targeted gene disruption. Science 1998; 282: 1911-1914

38. Tavassoli E, Saboory E, Teshfam M, Rasmi Y, Roshan-Milani S, Ilkhanizadeh B et al. Effect of prenatal stress on density of NMDA receptors in rat brain. Int J Dev Neurosci 2013 31: 790-795.

39. Stadler F, Kolb G, Rubusch L, Baker SP, Jones EG, Akbarian S. Histone methylation at gene promoters is associated with developmental regulation and region-specific expression of ionotropic and metabotropic glutamate receptors in human brain J Neurochem 2005; 94: 324-336.

40. Verges DK, Restivo JL, Goebel WD, Holtzman DM, Cirrito JR. Opposing synaptic regulation of amyloid- $\beta$ metabolism by NMDA receptors in vivo. $J$ Neurosci 2011; 31 11328-11337.

41. Cheng G, Yu Z, Zhou D, Mattson MP. Phosphatidylinositol-3-kinase-Akt kinase and p42/p44 mitogen-activated protein kinases mediate neurotrophic and excitoprotective actions of a secreted form of amyloid precursor protein. Exp Neurol 2002; 175 407-414.

42. Demars MP, Bartholomew A, Strakova Z, Lazarov O. Soluble amyloid precursor protein: a novel proliferation factor of adult progenitor cells of ectodermal and mesodermal origin Stem Cell Res Ther 2011; 2: 36

43. Wegiel J, Kuchna I, Nowicki K, Imaki H, Wegiel J, Marchi E et al. The neuropathology of autism: defects of neurogenesis and neuronal migration, and dysplastic changes. Acta Neuropathol 2010; 119: 755-770.

44. Tang G, Gutierrez Rios P, Kuo SH, Akman HO, Rosoklija G, Tanji K et al. Mitochondrial abnormalities in temporal lobe of autistic brain. Neurobiol Dis 2013; 54: 349-361.

45. Zampese E, Fasolato C, Pozzan T, Pizzo P. Presinilin-2 modulation of ER-mitochondria interactions: FAD mutations, mechanisms and pathological consequences. Commun Integr Biol 2011; 4: 357-360.

46. Zampese E, Fasolato C, Kipanyula MJ, Bortolozzi M, Pozzan T, Pizzo P. Presenilin 2 modulates endoplasmic reticulum (ER)-mitochondria interactions and $\mathrm{Ca} 2+$ cross-talk. Proc Natl Acad Sci USA 2011; 108: 2777-2782.

47. Aida $T$, Ito $Y$, Takahashi YK, Tanaka K. Overstimulation of NMDA receptors impairs early brain development in vivo. PLoS One 2012; 7: e36853.

48. Sokol DK, Chen D, Farlow MR, Dunn DW, Maloney B, Zimmer JA et al. High levels of Alzheimer beta-amyloid precursor protein (APP) in children with severely autistic behavior and aggression. J Child Neurol 2006; 21: 444-449.
49. Ashwood P, Van de Water J. Is autism an autoimmune disease? Autoimmun Rev 2004; 3 : 557-562.

50. Bailey AR, Hou H, Song M, Obregon DF, Portis S, Barger S et al. GFAP expression and social deficits in transgenic mice overexpressing human SAPP $\alpha$. Glia 2013; 61 : $1556-1569$.

51. Laurence JA, Fatemi SH. Glial fibrillary acidic protein is elevated in superior frontal, parietal and cerebellar cortices of autistic subjects. Cerebellum 2005; 4: 206-210.

52. Vargas DL, Nascimbene C, Krishnan C, Zimmerman AW, Pardo CA. Neuroglial activation and neuroinflammation in the brain of patients with autism. Ann Neurol 2005; 57 : $67-81$

53. Li X, Chauhan A, Sheikh AM, Patil S, Chauhan V, Li XM et al. Elevated immune response in the brain of autistic patients. J Neuroimmunol 2009; 207: 111-116.

54. Wei H, Zou H, Sheikh AM, Malik M, Dobkin C, Brown WT et al. IL-6 is increased in the cerebellum of autistic brain and alters neural cell adhesion, migration and synaptic formation. J Neuroinflammation 2011; 8: 52.

55. Sabo SL, Lanier LM, Ikin AF, Khorkova O, Sahasrabudhe S, Greengard $P$ et al. Regulation of beta-amyloid secretion by FE65, an amyloid protein precursor-binding protein. J Biol Chem 1999; 274: 7952-7957.

56. Xie Z, Dong Y, Maeda U, Xia W, Tanzi RE. RNA interference silencing of the adaptor molecules ShcC and Fe65 differentially affect amyloid precursor protein processing and Abeta generation. J Biol Chem 2007; 282: 4318-4325

57. Suh J, Lyckman A, Wang L, Eckman EA, Guénette SY. FE65 proteins regulate NMDA receptor activation-induced amyloid precursor protein processing. J Neurochem 2011; 119 : 377-388.

58. Zhang $B$, Zhang $Y$, Wang $Z$, Zheng $Y$. The role of Mg2 + cofactor in the guanine nucleotide exchange and GTP hydrolysis reactions of Rho family GTP-binding proteins. J Biol Chem 2000; 275: 25299-25307.

59. Lu SY, Huang ZM, Huang WK, Liu XY, Chen YY, Shi T et al. How Calcium inhibits the magnesium-dependent kinase gsk3 $\beta$ : a molecular simulation study. Proteins 2013; 81: 740-753.

60. He $\mathrm{P}$, Shen $\mathrm{Y}$. Interruption of beta-catenin signaling reduces neurogenesis in Alzheimer's disease. J Neurosci 2009; 29: 6545-6557.

61. Strambi M, Longini M, Hayek J, Berni S, Macucci F, Scalacci E et al. Magnesium profile in autism. Biol Trace Elem Res 2006; 109: 97-104.

62. Andrási E, Páli N, Molnár Z, Kösel S. Brain aluminum, magnesium and phosphorus contents of control and Alzheimer-diseased patients. J Alzheimers Dis 2005; 7: 273-284.

63. Lelord G, Muh JP, Barthelemy C, Martineau J, Garreau B, Callaway E. Effects of pyridoxine and magnesium on autistic symptoms-initial observations. J Autism Dev Disord 1981; 11: 219-230.

64. Frye RE, Rossignol D, Casanova MF, Brown GL, Martin V, Edelson S et al. A review of traditional and novel treatments for seizures in autism spectrum disorder: findings from a systematic review and expert panel. Front Public Health 2013; 1: 31.

65. Wain HM, Lush MJ, Ducluzeau F, Khodiyar VK, Povey S. Genew: The Human Gene Nomenclature Database, 2004 updates. Nucleic Acids Res 2004; 32: D255-D257.

66. Hooper SD, Bork P. Medusa: a simple tool for interaction graph analysis. Bioinformatics 2005; 21: 4432-4433

67. Gentleman RC, Carey VJ, Bates DM, Bolstad B, Dettling M, Dudoit S et al. Bioconductor: open software development for computational biology and bioinformatics. Genome Biol 2004; 5 : R80.

68. Smoot ME, Ono K, Ruscheinski J, Wang PL, Ideker T. Cytoscape 2.8: new features for data integration and network visualization. Bioinformatics 2011; 27: 431-432.

69. Ginsberg MR, Rubin RA, Falcone T, Ting AH, Natowicz MR. Brain transcriptional and epigenetic associations with autism. PLoS One 2012; 7: e44736.

70. Castro MA, Filho JL, Dalmolin RJ, Sinigaglia M, Moreira JC, Mombach JC et al. Viacomplex: software for landscape analysis of gene expression networks in genomic context. Bioinformatics 2009; 25: 1468-1469.

Cell Death and Disease is an open-access journal published by Nature Publishing Group. This work is licensed under a Creative Commons Attribution-NonCommercialShareAlike 3.0 Unported License. The images or other third party material in this article are included in the article's Creative Commons license, unless indicated otherwise in the credit line; if the material is not included under the Creative Commons license, users will need to obtain permission from the license holder to reproduce the material. To view a copy of this license, visit http://creativecommons.org/ licenses/by-nc-sa/3.0/ 